\title{
Jasmonate Induced Inhibition of Colletotrichum lindemuthianum (Sacc. \& Magnus) Briosi \& Cavara in Lablab purpureus L. Sweet under in vitro Conditions
}

\author{
Ramasamy Kuralarasi ${ }^{1}$, Veerapandian Thangapandian ${ }^{2}$ and Krishnasamy Lingakumar ${ }^{1 *}$ \\ ${ }^{1}$ Centre for Research and PG Studies in Botany, India \\ ${ }^{2}$ Department of Zoology, Ayya Nadar Janaki Ammal College (Autonomous), India
}

Submission: March 01, 2018; Published: April 06, 2018

"Corresponding author: Krishnasamy Lingakumar, Department of Zoology, Ayya Nadar Janaki Ammal College (Autonomous), India, Tel: 09486736867; Email: krish.lingakumar@gmail.com

\begin{abstract}
The objective of this study was to evaluate the protective role of Jasmonic acid in Lablab purpureus L. Sweet against Anthracnose disease. Colletotrichum lindemuthianum was cultured in PDA medium supplemented with $0.5 \mu \mathrm{M}, 1 \mu \mathrm{M}, 2 \mu \mathrm{M}$ and $5 \mu \mathrm{M}$ concentrations of Jasmonate. Supplementation of JA was found to inhibit radial growth of $C$. lindemuthianum after 7 days incubation. The effective concentration of JA was $1 \mu \mathrm{M}$ with $50 \%$ of inhibition of radial growth. When fresh pods of Lablab purpureus were punctured to a $0.5 \mathrm{~cm}$ of diameter using a sterile cork borer and replaced with Colletotrichum lindemuthianum culture discs with or without JA solution the lesions began to appear after $7 \mathrm{days}$ at 24 ${ }^{\circ} \mathrm{C}$ incubation. JA at $2 \mu \mathrm{M}$ concentration significantly reduced the lesion to $0.7 \mathrm{~cm}$. Thus, the in vitro study helps to confirm the protective role of JA.
\end{abstract}

Keywords: Anthracnose; Beans; Colletotrichum lindemuthianum; Jasmonic acid; Lesion

\section{Introduction}

Jasmonic acid (JA) is a member of plant growth regulators named jasmonates and its derivatives stimulate various physiological processes, including tendril twisting, formation of pollen, tubers and fruit ripening. They also enhance plant defense responses to mechanical impact, wounding caused by insects and pathogenic infections [1]. JA occurs ubiquitously in plants exhibiting hormone-like properties, regulating various physiological processes leading to growth and development, promotion of leaf senescence [2]. JA is a fatty-acid-derived signaling molecule, is involved in several aspects of plant biology including pollen and seed development, defense against wounding, ozone, insect pests and microbial pathogens [3]. The high concentrations of JA inhibits root growth and stem elongation and reduces its fresh and dry weight, as well as protein content and proline accumulation in plants [4]. Such reports are available based mainly on the studies carried out on intact differentiated leaves with exogenous application of jasmonate.
Till now it is considered that jasmonate particularly methyl esters of JA as a chemical stress agent mimicking the effect of that appear in response to external stress factors inducing senescence.

India is largest pulse producing country in the world, its having 18.45 million tonnes of pulse production from an area of 23.97 million ha [5]. Anthracnose caused by C. lindemuthianum is a devastating soil and air borne disease of pulse plants in India. Colletotrichum lindemuthianum (Sacc. and Magnus) Lams. Scrib., the causal organism of pulse anthracnose, is a serious soil born as well as seed borne pathogen of pulse crops throughout the world. Weather variables have profound impacts on the disease occurrence. Optimal temperature $\left(22-29{ }^{\circ} \mathrm{C}\right)$ optimum, with high relative humidity $(80 \%)$ and optimal rainfall was found favorable for anthracnose disease development Aggarwal et al. [6]. Lablab purpureus is consumed principally for its dry beans, shell beans and green pods and also a major source of dietary protein that complements carbohydrate-rich sources such as 
rice, maize and cassava. The crop is a rich source of dietary fibers, minerals and certain vitamins [7]. Field losses in these regions, due to seedling, leaf, stem and pod infections, are up to $90 \%$ under climatic conditions favourable to the disease. Symptoms are broad ranging and include stem rot, dieback and seedling blight. Fruits are affected during the pre and post harvested period [8]. When C. lindemuthianum attack bean leaves, it causes dark brown necrotic lesions and decrease leaf photosynthesis activity [9]. Yield loss is due to early leaf senescence and plant death, shrunken seed and an increase in the amount of diseased seed that has lesions on its coat. Management strategies used to minimize seed borne infection include host resistance, cultural and chemical control methods. Harvesting drying and post harvest processing and storage operations can also be used to reduce the spread and to eradicate seed borne pathogens [10]. P. fluorescens was effective controlling of common bean anthracnose [11].

The present study is aimed to investigate the protective effects of Jasmonate in Lablab purpureus $L$. Sweet against Anthracnose tested in vitro.

\section{Material and Methods}

\section{Fungal subculture|}

Colletotrichum lindemuthianum active culture was purchased from Microbial Type Culture Collection at Chandigarh, India and subcultured into Potato dextrose agar medium. A small piece of the mycelium from the margin of the colony on PDA. The plates were incubated at $24^{\circ} \mathrm{C}$ for a period of 14 days.

\section{The effects of JA on the mycelial growth of Colletotrichum lindemuthianum}

The effects of Jasmonate (Sigma-Aldrich, St Louis, U.S.A.) on the mycelial growth of Colletotrichum lindemuthianum were assessed in vitro PDA amended with $0.5 \mu \mathrm{M}, 1 \mu \mathrm{M}, 2 \mu \mathrm{M}$ and $5 \mu \mathrm{M}$ of JA. JA was initially dissolved in $100 \mu$ l of acetone and further concentrations were prepared using sterile distilled water. JA solutions were autoclaved prior to use. For in vitro assessment a $0.5 \mathrm{~cm}$ diameter mycelial disc from active PDA culture of Colletotrichum lindemuthianum was placed fungus-side facing down at the centre of petri dish. A control with acetone was used as a negative control whereas mycelial discs placed at the centre acted as a positive control. The inoculated plates were incubated at $4{ }^{\circ} \mathrm{C}$ and $24{ }^{\circ} \mathrm{C}$ for a brief up to 14 days.

\section{Inoculation of bean pods}

The mature bean pods were selected and the pods were surface sterilized using $100 \%$ ethanol and $0.1 \%$ mercuric chloride. The pods were punctured to diameter of $0.5 \mathrm{~cm}$ using a sterile cork borer. For inoculating purpose, $0.5 \mathrm{~cm}$ diameter disc was removed from the edge of an actively growing culture and placed mycelium-side down on the wound. Bean pods were inoculated with plugs of sterile PDA were used as control. The inoculated pods were placed in sterile plastic container on moist filter paper and inoculated at $24^{\circ} \mathrm{C}$ and $4{ }^{\circ} \mathrm{C}$. The diameter of the lesions was measured periodically.

\section{Statistical analysis}

Differences between the concentrations of JA on the radial growth of the fungus and the differences between lesion diameters on bean pods were evaluated by analysis of variance (ANOVA). Fisher's least significance difference (LSD) at P 1/4 0.05 was used to compare the radial growth means.

\section{Result and Discussion}

\section{Morphology of C. lindemuthianum}

Colonies on PDA grew quickly, occupying the whole surface of the Petri dishes within $7 \mathrm{~d}$. They were white to dark grey with orange in colour colonies. They were powdery and well sporulated and had a few tufts associated with fruiting bodies the production of conidiomata was mainly restricted to the central areas, and the reverse was grayish-brown.

\section{Effect of JA concentrations on colletotrichum lindemuthianum growth in vitro}

The Colletotrichum lindemuthianum culture used in this study was progressively inhibited with increasing concentrations of JA from $0.5 \mu \mathrm{M}, 1 \mu \mathrm{M}, 2 \mu \mathrm{M}, 5 \mu \mathrm{M}$. Fungal growth was significantly affected by all concentrations of Jasmonate after $7 \mathrm{~d}$ of incubation (Figure $1 \mathrm{a}$ ). $1 \mu \mathrm{M}$ concentrations of JA $50 \%$ $(2.5 \mathrm{~cm})$ inhibited the mycelial growth compared to the control. The inhibition percentages gradually decreased at $2 \mu \mathrm{M}$ and $5 \mu \mathrm{M}$ with inhibition ratios of $2.3 \mathrm{~cm}$ and $2.0 \mathrm{~cm}$ respectively (Figure 1b). Similar reports were the inhibitory effect of MeJA was also evident in the mycelium growth (Figure 1b). After one day, the mycelial growth was found to be reduced in the PDA medium containing MeJA at a concentration 0.1 and at $1 \mathrm{mM}$ Pczynska \& Paulina [12]. The control solution with acetone had no effect on the growth of Colletotrichum lindemuthianum. Our present study reveals that the use of JA on Lablab purpureus is effective in reducing anthracnose in Bean pods. Beans treated with the higher volume of JA solutions showed a significantly reduction in lesion diameter compared to control plants. There were significantly differences between the effects of JA concentrations and incubation temperature on the lesion size of Colletotrichum lindemuthianum. JA was most effective when beans were stored at room temperature. When applied at identical concentrations, the compound was reported to inhibit, nearly at an identical level, in vitro germination of A. alternata (Fr.) Keissl. Isolated from stored apples [13]. In comparison with controls, the two JA concentrations significantly reduced lesion diameters at 24 ${ }^{\circ} \mathrm{C}$. However, after storage at $4{ }^{\circ} \mathrm{C}$, the anthracnose lesions in the control were significantly smaller and no significantly differences in lesion size were observed in bean pods treated with varying doses of JA the controls. Howe, 2005 indicate that this substance 
activates JA synthesis in infected hosts. In vitro JA significantly inhibited fungal growth of Colletotrichum lindemuthianum and significant differences were observed in the mean growth rates of
Colletotrichum lindemuthianum at all concentrations compared to control. Increase in JA response to attack occur both locally and systematically [14].

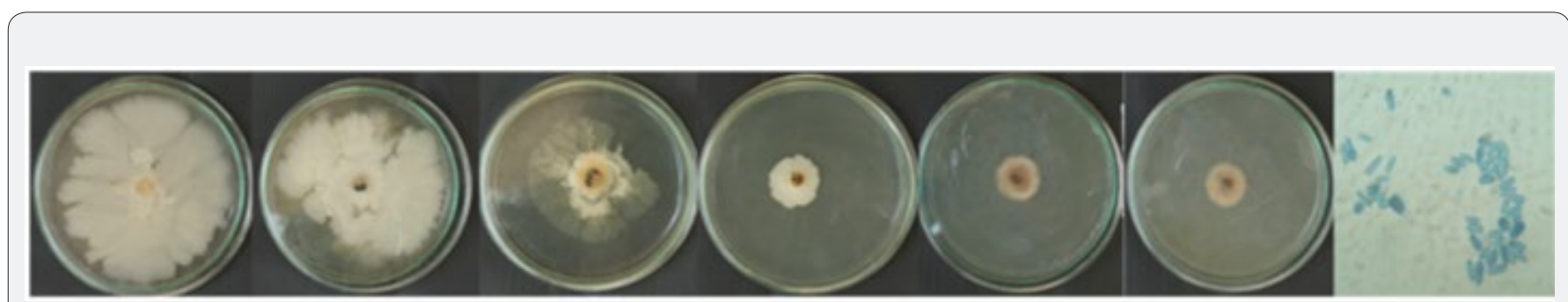

Figure 1a: Mycelial growth of Colletotrichum lindemuthianum on PDA supplemented with $0.5 \mu \mathrm{M}, 1 \mu \mathrm{M}, 2 \mu \mathrm{M}, 5 \mu \mathrm{M}$ of JA. Colony diameter was calculated $7 \mathrm{~d}$ after treatment.

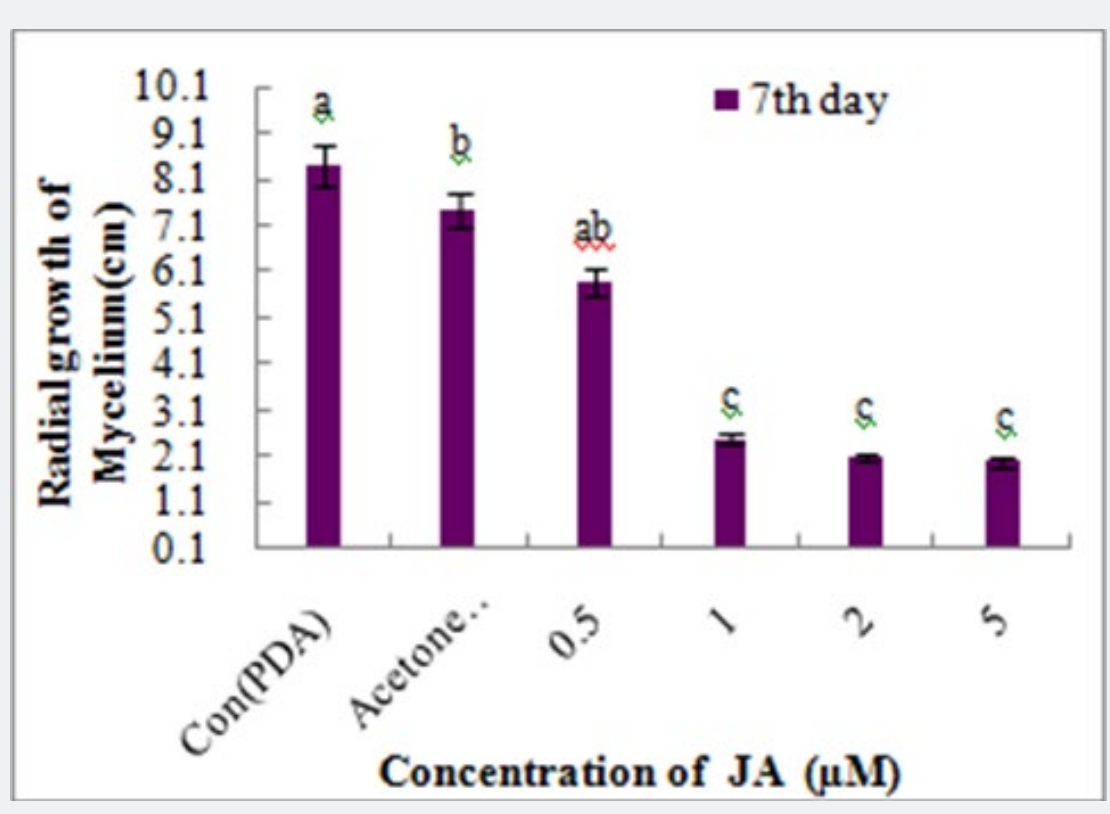

Figure 1b: Mycelial radial growth induced by four $0.5 \mu \mathrm{M}, 1 \mu \mathrm{M}, 2 \mu \mathrm{M}, 5 \mu \mathrm{M}$ of JA concentrations.

\section{Effect of JA on the inoculated bean pods}

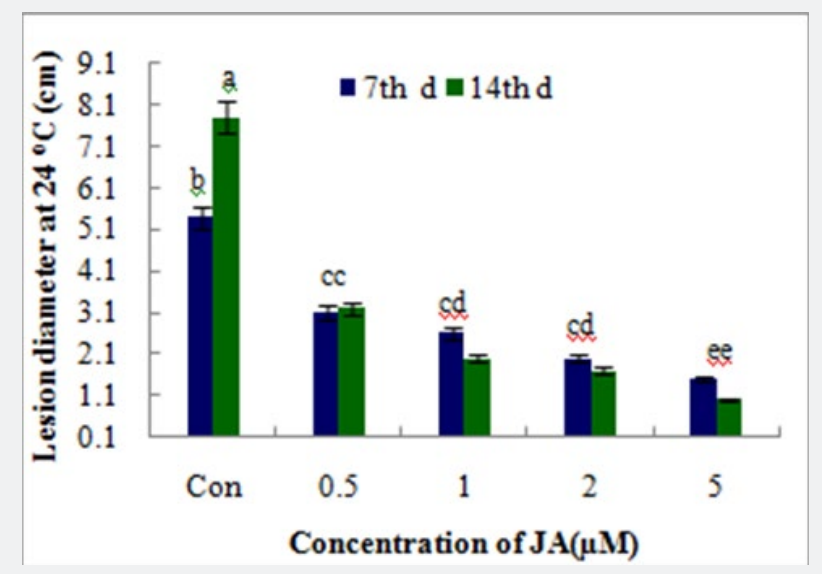

Figure 2: Lesion diameters $(\mathrm{cm})$ of pods treated with JA and inoculated with Colletotrichum lindemuthianum $7 \& 14 \mathrm{~d}$ after inoculation at 24 ${ }^{\circ} \mathrm{C}$. 


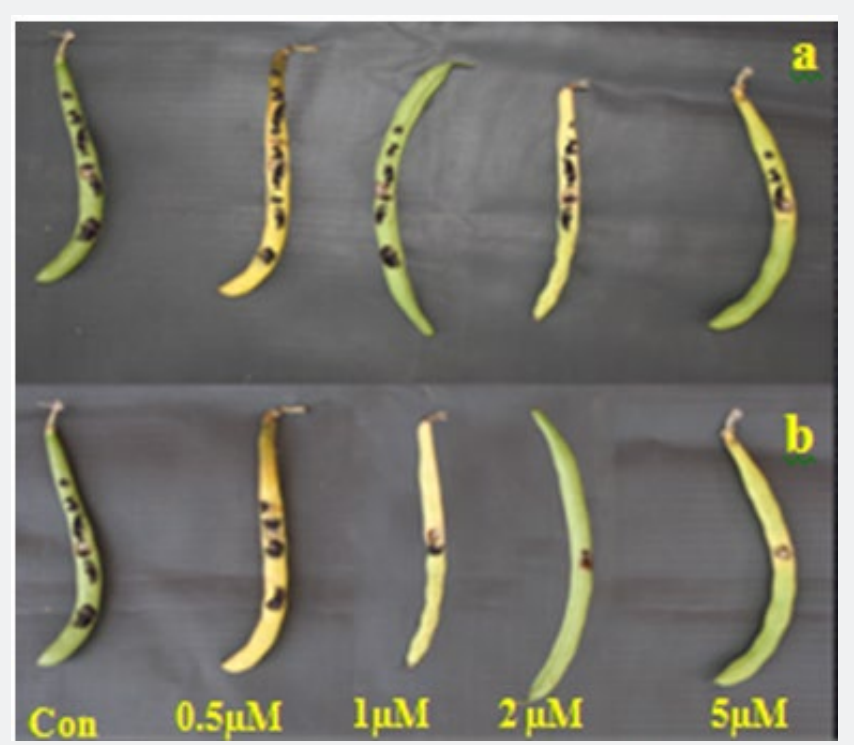

Figure 3: Anthracnose symptoms on Bean pods inoculated with C. lindemuthianum and stored at $4{ }^{\circ} \mathrm{C} \& 24^{\circ} \mathrm{C}$ respectively.

On the inoculated bean pods, JA solutions $2 \mu \mathrm{M}$ and $5 \mu \mathrm{M}$ significantly reduced the lesion size at $24{ }^{\circ} \mathrm{C} 14 \mathrm{~d}$ after inoculation. Lesion diameter on the inoculated bean pods reduce at $24{ }^{\circ} \mathrm{C}$ in the concentration of $2 \mu \mathrm{M}$ and $5 \mu \mathrm{M}$ of JA which are dark brown, circular infections formed. They appeared shriveled lesions were delimited by a round development symptoms and presence of conidiomata were visible after $7 \mathrm{~d}$ incubation (Figure 2). Jasmonate significantly reduced the lesion size of bean pods treated with $2 \mu \mathrm{M}$ and $5 \mu \mathrm{M}$ lesion diameter $0.7 \mathrm{~cm}$ and $0.6 \mathrm{~cm}$ respectively on treated beans was significantly reduced at 24 ${ }^{\circ} \mathrm{C}$ compare to control $(7.8 \mathrm{~cm})$ at $14 \mathrm{~d}$ incubation. However, significantly differences were only detected between the $5 \mu \mathrm{M} \mathrm{JA}$ concentration and the corresponding control when bean pods were stored. Anthracnose lesions on bean pods maintained at 4 ${ }^{\circ} \mathrm{C}$ were smaller that on stored at $24{ }^{\circ} \mathrm{C}$ and JA did not reduce the diameter lesion at the cold storage temperature (Figure 3). Environmental factors as well as the types of pathogen infecting plants and the concentration of JA relative to each other, can affect the outcome of resulting cross talk [15].The experimental data in this study demonstrate that the JA signaling protects against necrotrophic pathogens and insects [16-20].

\section{Pathogenicity on the inoculated bean pods}

The Colletotrichum lindemuthianum evaluated in this study was pathogenic to bean pod, however bean pods were more susceptible. The lesions were cut into small piece and surface sterilized into $0.1 \%$ mercuric chloride segments were placed into PDA. The plates were inoculated $7 \mathrm{~d}$ the orange brown color colonies formed the mycelial mats were stained by lactophenol cotton blue the rod shape spore confirm the presence of Colletotrichum lindemuthianum (Figure 4).

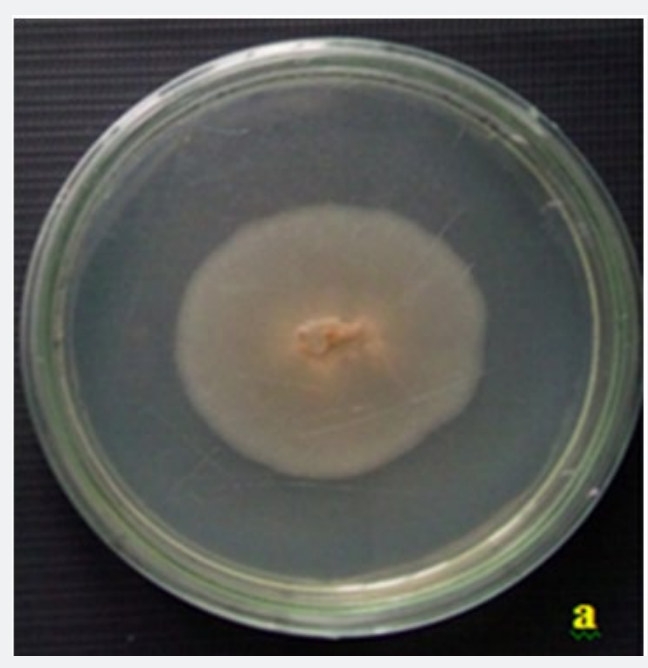

Figure 4a: Figure 4a: Pathogenicity assay of inoculated pods. 




Figure 4a: Spores.

Our findings show that JA offers a safe alternative to synthetic fungicides in postharvest anthracnose disease and could be considered as a potential agrochemical of low environmental impact.

\section{Acknowledgment}

Authors thanks to Principal and Management of Ayya Nadar Janaki Ammal College, Sivakasi for providing facilities to do the present study.

\section{References}

1. .-Creelman RA, Mullet JE (1997) Biosynthesis and Action of Jasmonates in Plants. Annu Rev Plant Physiol 48: 355-381.

2. He Y, Fukushige H, Hildebrand DF, Gan S (2002) Evidence supporting a role of jasmonic acid in Arabidopsis leaf senescence. Plant Physiol 128(3): 876-884.

3. Li, CY, Williams MM, Loh YT, Lee GI, Howe GA (2002) Resistance of cultivated tomato to cell content-feeding herbivores is regulated by the octadecanoid-signaling pathway. Plant Physiol 130(1): 494-503.

4. Kumari GJ, Sudhakar C (2003) Effects of Jasmonic Acid on Groundnut during Early Seedling Growth. Biol Plant 47(3): 453-456.

5. Kaura L, Gilla KK, Kingraa PK, Siraria A (2014) Archives of Phytopathology and Plant Protection. 47: 643-651.

6. Aggarwal SK, Mali BL, Rajput LS, Choudhary M (2017) Epidemiology of anthracnose of black gram caused by Colletotrichum lindemuthianum. InternlJ Agri Sci 9(2): 3656-3657.

7. Gepts P, Aragão FL, de Barros E, Blair MW, Brondani R (2008) Genomics of Phaseolus Beans, a Major Source of Dietary Protein and Micronutrients in the Tropics. In: Genomics of Tropical Crop Plants. Moore PH \& Ming R (Eds.), Springer, Germany, pp. 113- 140.

8. Sutton BC (1992) The genus Glomerella and its anamorph Colletotrichum. In: Colletotrichum biology, pathogenicity, and control. Bailey JA \& Jeger MJ (Eds.), CAB International, Wallingford, UK, pp. 210298.

9. Bassanezi RB, Amorin L, Filho AB, Hau B, Berger RD (2001) Accounting for photosynthetic efficiency of bean leaves with rust, angular leaf spot and anthracnose to assess crop damage. Plant Pathol 50(4): 443-452.
10. Mudawi HI, Idris MO, El Balla MA (2009) Anthracnose Disease in Common Bean (Phaseolus vulgaris L.) in Shambat, Sudan: Disease incidence, severity and effect on yield. UK J Agric Sci 17: 118-130.

11. Amin M, Fitsum S, Selvaraj T, Mulugeta N (2014) Field Management of Anthracnose (Colletotrichum lindemuthianum) in Common Bean through Fungicides and Bioagents. Adv Crop Sci Technol 2: 124.

12. Pczynska KE, Paulina K (2012) The phytohormone methyl jasmonate as an activator of induced resistance against the necrotroph Alternaria porri f. sp. solani in tomato plants. J Plant Inter 7(4): 307-315.

13. Kepczynska E, Kepczynski J (2005) Inhibitory effect of methyl jasmonate on development of phythopathogen Alternaria alternata (Fr.) Keissl and its reversal by ethephon and ACC. Acta Physiol Plant 27(4A): 491-496.

14. Audenaert K, De Meyer GB, Hofte MM (2002) Abscisic acid determines basal susceptibility of tomato to Botrytis cinerea and suppresses salicylic acid-dependent signaling mechanisms. Plant Physiol 128(2): 491-501.

15. Spoel SH, Dong X (2012) How do plants achieve immunity? Defence without specialized immune cells. Nat Rev Immunol 12(2): 89-100.

16. Glazebrook J (2005) Contrasting mechanisms of defense against biotrophic and necrotrophic pathogens. Annu Rev Phytopathol 43: 205-227.

17. Bailey JA, Jeger MJ (1992) Colletotrichum: Biology, Pathology and Control, Wallingford, UK, pp. 127-139.

18. Delker C, Stenzel I, Hause B, Miersch O, Feussner I, et al. (2006) Jasmonate biosynthesis in Arabidopsis thaliana - enzymes, products, regulation. Plant Biol 8(3): 297-306.

19. Doares SH, Narvaez-Vasquez J, Conconi A, Ryan CA (1995) Salicylic acid inhibits synthesis of proteinase inhibitors in tomato leaves induced by systemin and Jasmonic acid. Plant Physiol 108(4):1741-1746.

20. Howe GA, Lightner J, Browse J, Ryan CA(1996) An octadecanoid pathway mutant (JL5) of tomato is compromised in signaling for defense against insect attack. Plant Cell 8(11): 2067-2077. 
This work is licensed under Creative Commons Attribution 4.0 License

DOI: 10.19080/ARTOAJ.2018.15.555950
Your next submission with Juniper Publishers will reach you the below assets

- Quality Editorial service

- Swift Peer Review

- Reprints availability

- E-prints Service

- Manuscript Podcast for convenient understanding

- Global attainment for your research

- Manuscript accessibility in different formats

( Pdf, E-pub, Full Text, Audio)

- Unceasing customer service

Track the below URL for one-step submission https://juniperpublishers.com/online-submission.php 